\title{
Local Economic Impacts of Investments in Community Technology Centers: An Empirical Investigation
}

$\begin{array}{cl}\text { Krishna Jayakar } & \begin{array}{l}\text { Penn State University, USA } \\ \text { kpj1@psu.edu }\end{array} \\ & \text { Penn State University, USA } \\ \text { Jenna Grzeslo } & \text { Corresponding Author. } \\ & \text { jmg614@psu.edu }\end{array}$

Although community technology centers (CTCs) provide a host of services that may have economic consequences, few studies have attempted to empirically assess the impact of CTCs on local communities. Controlling for broadband availability and demographics, this study found that there is a small but positive and significant impact of CTC quality on median household income, at the county level. In addition to bridging the digital divide for disadvantaged populations, our research shows that there are also quantifiable economic benefits from CTC investments.

\section{Introduction}

Community technology centers (CTCs) have a long pedigree, both in the United States and abroad. Historically, the motivation behind CTCs was to extend information and communication technology (ICT) access and training services to communities and individuals deprived of them because of low socioeconomic status or lack of digital literacy. Beginning in the 1990s, CTCs, also called public computing centers (PCCs) and telecenters, have been established in practically all countries around the world, especially in rural areas, congested urban centers, and remote and far-flung territories (Ariyabandu, 2009). A 25-country survey in 2009 found that more than 248,000

Jayakar, K., Grzeslo, J. (2017). Local economic impacts of investments in community technology centers: an empirical investigation. The Journal of Community Informatics, 13(1), $137-151$.

Date submitted: 2016-02-09. Date accepted: 2017-02-27.

Copyright (C), 2016 (the authors as stated). Licensed under the Creative Commons AttributionNonCommercial-ShareAlike 2.5. Available at: www.ci-journal.net/index.php/ciej/article/view/1304 
libraries, telecenters, cybercafés and other establishments provided some form of internet access to the public (Gomez, Ambikar \& Coward, 2011).

Despite this two-decade-long experience with CTCs, efforts to assess the impacts of CTCs on local communities are relatively infrequent. O'Neil (2002) identified five areas within which CTCs may be assessed: strengthening democracy, building social capital, empowering individuals, creating a sense of community, and economic development opportunities. However, few studies have attempted to empirically assess these impacts. A comprehensive literature review several years ago found that empirical assessments of public access centers focused primarily on "venue performance and sustainability, users, usage patterns and downstream impacts" (p. 1) with downstream impacts receiving the least attention (Sey \& Fellows, 2009). A review of the more recent literature reveals little change in the situation. Of the few articles examining downstream impacts, Jayakar and Park (2012) and Park and Jayakar (2013) examined the patterns of federal funding for PCCs, to ascertain whether funds were allocated efficiently to the locations with greatest expected demand. Gomez and Camacho (2013) examined the demographic profile of CTC users and found that public access venues narrow the digital divides across age, education, gender and income barriers. Jaeger and Fleischmann (2013) found that internet access through CTCs contributed to better public awareness of government programs. But none of these recent studies have examined the broader economic impacts of CTCs.

And yet, the literature on ICTs and development has shown quite convincingly that CTCs may be expected to have local economic impacts. The literature has shown that ICTs in general contribute to economic growth by substituting for other production inputs and reducing transaction costs. In addition to providing access to ICTs and broadband to the public, CTCs provide a host of services that might have economic consequences: digital literacy training, small business services, job training, etc. These services may cumulatively be expected to have effects on local economic growth, through encouraging small business entrepreneurship, lowering unemployment and enhancing local labor skills. Identifying the magnitude of these economic consequences, if any, is critical to ensuring continuing public support to CTCs.

In this context, this paper seeks to analyze the local economic impact of investments in CTCs. However, a challenge in research of this nature is the availability of data, since no centralized database of CTC investments exists - CTCs are run by a wide variety of entities including municipalities and city governments, charitable foundations, industry and trade groups, and public libraries. To solve this problem, we use data on a subset of CTCs, namely computing centers attached to public libraries, which is available from the Institute of Museum and Library Services (IMLS). This database is combined with broadband availability data from the National Broadband Map, and the latest available installment of the annual County Business Patterns survey from the U.S. Bureau of the Census. As described in the methodology section, we seek to examine whether public access to the internet through CTCs was significantly correlated to household incomes at the county level, after controlling for other explanatory factors. This line of investigation addresses whether investments in CTCs may be advocated only on 
considerations of equity and social justice, or whether there is an economic rationale that can justify such investments.

The paper is organized as follows. In the next section, we first define "community technology centers" to differentiate them from other initiatives that also seek to improve public access to technology. We also examine the types of funding available for CTCs, and the types of services offered by these centers. The next section examines the literature on CTCs and economic development. As pointed out previously, there have been relatively few empirical studies that have specifically examined CTCs and economic development. To guide our research, we therefore consult the broader literature on the economic impacts of ICTs. Our methodology and data sources are discussed in the section that follows. We then present the results of our analysis, and then proceed to discussion and conclusions.

\section{Defining CTCs}

Very broadly, efforts to bridge the digital divide have taken two forms: promoting residential access, and creating publicly-accessible community resources. Among the latter are efforts to create internet infrastructures such as municipal broadband and wi-fi systems. CTCs adopt a different approach to bridging the digital divide, by creating a public location where computers, ICTs and broadband connections are made available. However, many institutions may provide the same function. The first step therefore is to define CTCs in order to specifically differentiate CTCs from other centers that provide similar services and to identify the subject matter of the paper. The goal of CTCs is to bridge the digital divide by increasing not only access to ICTs but also the skills necessary to effectively use ICTs (Kaiser, 2005). The United States Department of Education (2005) states,

Community Technology Centers provide computer access and educational services using information technology. In general, people who visit CTCs do not own computers, and many do not have access to computers at work or school. CTCs make computers, the Internet, and various software packages available (online).

The difference between CTCs and other types of technology centers is unclear. The National Telecommunications and Information Administration (NTIA) defines PCCs as, "projects to establish new public computer facilities or up- grade existing ones that provide broadband access to the general public or to specific vulnerable populations, such as low-income individuals, the unemployed, seniors, children, minorities, and people with disabilities" (NTIA, 2010, online). Moreover, a public computing center is:

a place, including but not limited to community colleges, libraries, schools, youth centers, employment service centers, Native American chapter houses, community centers, senior centers, assistive technology centers for people with disabilities, community health centers, and Neighborhood Network Centers in public housing developments, that provide broadband access to the general 
public or a specific vulnerable population, such as low-income, unemployed, aged, children, minorities, and people with disabilities (Department of Commerce, 2009, p. 33109).

Though not explicitly stated in these definitions, a critical aspect of CTCs and PCCs is that no fees or other charges are attached to accessing their facilities. However, not all technology centers have the same policy. Haseloff (2005:54) defined cybercafés as "forprofit facilities, open to the general public to access the Internet, other network facilities and/or a variety of information technology tools on a temporary contract basis (pay per use) without the necessity for the users to own hardware or software themselves." In contrast to CTCs and PCCs that are free to the public to use, cybercafés require a payment for services; they thus provide broadband and ICT access to individuals who may not be able to afford residential access, but are nevertheless affluent enough to pay cybercafé fees.

The choice of business model highlights another critical difference between CTCs/ PCCs and cybercafés. Whereas cybercafés are for-profit businesses, CTCs and PCCs are typically not. Funding for CTCs can come from a variety of sources including municipalities and city governments, charitable foundations, industry and trade groups, public libraries and grants. Larose et al. (2014) reported that 5\% of funding (around $\$ 190$ million) from the federal Broadband Technology Opportunities Program was allocated for PCCs. Various conditions might be attached to these public subsidies: for example, grant-funded CTCs must provide services in disadvantaged areas (U.S. Department of Education, 2004).

CTCs and PCCs may also offer a broader array of services than cybercafés. The most basic service offered by CTCs is creating a physical space for individuals to access the Internet (Mandal, Bishop, McClure, Bertot, \& Jaeger, 2010). The U.S. Department of Education (2004) lists five categories in which CTCs should offer services: adult education, afterschool activities, career development, small business activities, and activities that help individuals secure technology for their homes. Digital literacy education is also a key service offered by CTCs but likely overlaps with other types of services. The goal of adult education is increasing literacy among adults. Afterschool activities include, but are not limited to youth support programs (Mandal et al., 2010, p. 282). In assessing five CTCs in the United States, London, Pastor, Servon, Rosner and Wallace (2010) suggest that CTCs can increase social capital through youth development.

In summary, the elements common to the definitions for PCCs and CTCs are the following: (1) they are commonly, but not always, affiliated with or operated by a community institution such as library, community center, or school; (2) they provide access to not only broadband or other telecommunications connectivity but also devices such as computers, tablets or laptops and the associated software (and in this sense, they may be differentiated from other digital divide initiatives such as municipal wi-fi networks, that only provide broadband access); (3) they provide a variety of programs, such as literacy, computer training, and other educational services based on ICTs and broadband; (4) they, quite usually, target a specific underserved population, such as low- 
income people, children, or persons with disabilities; and (5) they usually make their services available for free to their communities, and therefore require subsidies from the local or federal government, charitable foundations, or industry groups.

In the rest of this paper, our references to CTCs should be understood in light of the above description: community institutions providing access to broadband, devices, software, and a variety of training programs, to a target population of underserved individuals, for free. Our analysis and conclusions do not refer to other types of community informatics programs, such as for-profit businesses, community broadband initiatives or municipal wi-fi networks.

\section{CTCs and economic development}

As stated previously, CTCs provide a variety of services to their clients including adult education, afterschool activities, career development, small business activities, and digital literacy programs designed to encourage broadband access (U.S. Department of Education, 2004). In addition, CTCs enable individuals to avail of online job search and career building services, and small businesses to access information about government loan programs and taxes. A report of activities at 6 CTCs documented the following effects: they facilitated family and community involvement in public schools; increased the participants' self-efficacy with computers; prepared people for the workforce; increased the time that school-age children spent reading, writing, and solving mathematics problems through after-school programs and provided activities for youth as alternatives to the traditional school learning environment (Penuel, Michalchik, Kim, \& Shear, 2001).

Many of these programs and services may be undoubtedly expected to have economic effects, through the creation of a more qualified and skilled workforce, and the facilitation of small business start-ups and local entrepreneurship. The broader literature on the economic consequences of broadband and ICT deployment make clear that such effects are reasonable to expect. The relationship between telecommunications and economic growth has been long recognized in the economics literature, ever since Jipp's (1963) pioneering work found a positive correlation between telephone density in a country and per capita Gross Domestic Product (GDP). By substituting for other production inputs and reducing transaction costs, telecommunications contributes to economic growth. Growth in turn makes more investment capital available for telecommunications development and also contributes to demand by increasing household income. The effect of broadband on economic growth has been explored in the more recent literature; to cite only a few, Crandall, Lehr and Litan (2007), Czernich, Falck, Kretschmer and Woessman (2011), Kolko (2010), and Whitacre, Gallardo, and Strover (2014).

This literature has found that the effect of broadband on economic growth is mediated by a number of factors, the first of which is productivity. Improvements in productivity generally enable a firm to increase output from the same set of inputs, or produce the same output while reducing capital and labor inputs (Fornefeld, Delaunay, \& Elixmann, 2008). Others have found that productivity in different industrial sectors responded 
differently to broadband deployment, with contrasting impacts on labor needs and wages, and thus on household and personal incomes (Crandall et al., 2007; Shideler, Badasyan \& Taylor, 2007).

In addition to the factors identified above, digital divide scholars have recently identified users' cognitive skills as a critical input into their utilization of broadband networks (Bach, Shaffer, Wolfson, 2013; Kent \& McClure, 2009; van Dijk, 2012). Specifically, users' digital literacy, defined as 'the ability to understand and use information in multiple formats from a wide range of sources when it is presented via computers" (Gilster, 1997, p. 1), has been found to impact the types of services access by users, as well as the amount of their utilization. Digital literacy is now recognized as a multi-dimensional concept involving several cognitive skills: interacting with computers and ICT equipment confidently; retrieving and evaluating online information; using broadband networks for communication and collaboration; creating and disseminating online content, etc. (Jayakar, 2012). Similarly, van Dijk (2012) identifies a number of medium related and content-related skills required to effectively utilize broadband: operational skills (how to operate devices); formal skills (browsing and navigating); information skills (retrieving and evaluating information); communication skills (connecting with other users and providing opinions); contentcreation skills (originating new content); and strategic skills (achieving professional and personal goals). User populations with these skills are more likely to be able to utilize broadband technologies more effectively, and therefore, will likely see greater economic impacts from broadband access and use. In other words, broadband access alone will be insufficient to account for its economic effects, unless we also account for users' ability to utilize the network. But in the absence of sufficient data on digital literacy for our statistical analysis, the education level of the user population is taken as a reasonable proxy. Prior research has found education levels, specifically the percentage of college and high school graduates in the workforce, as an influence on broadband impacts (Atasoy, 2013).

In summary, increased ICT and broadband availability may have diverse effects on economic growth and incomes in different markets. Also, these effects are mediated by the skill levels of the workforce, the demographics of the local population including the availability of labor. To assess the impact of services provided through CTCs on household income, we need to control for these factors including broadband availability.

\section{Methodology}

The goal of this study is to determine if there are economic effects of the services provided by CTCs at the community level. As discussed above, the services provided by CTCs include broadband and other telecommunications connectivity; access to devices such as computers, tablets or laptops and the associated software; programs such as digital literacy training, small business services, and other educational services based on ICTs and broadband. The quality of these services is therefore of great importance in assessing the impact of CTCs on their local communities. However, no comprehensive data exists on the economically-relevant programs and services offered through CTCs. Following Jayakar and Park (2012), we utilized data from the Institute of Museum and 
Library Services' (IMLS) database of public libraries to assess the quality of CTCs attached to them. Specifically, we used the following as proxies for CTC quality: the number of Internet accessible computers available to the public, the number of programs and service offerings; the number of databases available in the library's electronic reserves, and the number of hours for which the library is open.

The CTC data are aggregated to the county level, following Jayakar and Park (2012), Cronin, Parker, Colleran, and Gold (1993), Shuai (2010) and others. As a study of U.S. commuting patterns has demonstrated, the county as unit of analysis is small enough to capture local variations but large enough to constitute a reasonable labor market (Goetz, Han, Findeis, \& Brasier, 2010). Accordingly, data for all CTCs located in a county and attached to a public library are aggregated to the county level, and are used in the analysis indexed to population (see variable definitions in Table 1).

Table 1: Predictor and criterion variables

\begin{tabular}{|c|c|}
\hline Variable name & Definition \\
\hline INCOME2013 & Median household income (US Bureau of the Census, 2013) \\
\hline INCOME2012 & Median household income (US Bureau of the Census, 2012) \\
\hline$B R O A D B A N D$ & Percentage of county population with access to broadband (FCC, 2012) \\
\hline HSCHOOL & $\begin{array}{l}\text { Percentage of county population with a high school education (US Bureau } \\
\text { of the Census, 2012) }\end{array}$ \\
\hline MINORITY & Percentage of county population minority (US Bureau of the Census, 2012) \\
\hline WORKINGPOP & $\begin{array}{l}\text { Percentage of county population between the ages of 22-59 (US Bureau of } \\
\text { the Census, 2012) }\end{array}$ \\
\hline GPTERMS & $\begin{array}{l}\text { Number of internet accessible computers, indexed by county population } \\
\text { (IMLS, 2012) }\end{array}$ \\
\hline DATABASE & $\begin{array}{l}\text { Number of electronic databases available, indexed by county population } \\
\text { (IMLS, 2012) }\end{array}$ \\
\hline HOURS & Total number of hours open, indexed by county population (IMLS, 2012) \\
\hline
\end{tabular}

The dependent variable for the analysis was the county's median household income for the latest available year, namely 2013, collected from the U.S. Bureau of the Census. As a control against which to measure the influence of our main variable of interest (CTC services), we also collected the county median household income in 2012. Using prioryear household income as a control ensures that location-specific variables (regional and structural differences) that remain invariant year over year will be represented in the model, and only effects above and beyond these will be attributed to the other IVs included in the model. As another control, we used general broadband availability in the community since the literature has hypothesized that broadband and ICTs have an impact on economic growth (Crandall et al,, 2007; Czernich et al., 2011; Kolko, 2010; Whitacre et al., 2014). Data on broadband is available from the Federal 
Communications Commission's National Broadband Map (NBM). The NBM provides the percentage of households in each county having access to a broadband connection with at least $3 \mathrm{mbps}$ in download and $768 \mathrm{kbps}$ upload speed. To avoid reverse causality with our dependent variable (since increasing household income can affect broadband availability in markets as well) we used NBM data for 2012, retrieved for a previous study by one of the authors. We also used the percentage of adults in the county with at least a high school education as a control, since Atasoy (2013) and others have indicated the importance of education in economic growth. The percentage minority population and a measure of labor supply (the percentage of county population between the ages of 22-59) are used as other controls. The data definitions and sources for all our variables are provided in Table 1.

We specify the relationship between the variables as follows:

$$
\log \text { HHIncome }_{t}=\alpha+\beta_{1} \log \text { HHIncome }_{t-1}+\sum \beta_{j} X_{j}+e
$$

\section{Analysis}

Prior to regression analysis, descriptive statistics (Table 2) and correlations (Table 3) were calculated for all the variables in the study. The number of observations corresponds to all counties in the United States, in all 50 states. Relatively high correlations were noted between the CTC quality variables, GPTERMS, DATABASE and HOURS. To avoid multicollinearity, these variables are not included in the same regression models.

Table 2: Descriptive Statistics

\begin{tabular}{lrrr}
\hline Variables & Obs. & Mean & Std. dev. \\
\hline INCOME2013 & 3063 & 46194.37 & 11621.90 \\
INCOME2012 & 3103 & 46664.66 & 12523.76 \\
BROADBAND & 3141 & .897 & .170 \\
HSCHOOL & 3124 & .773 & .089 \\
MINORITY & 3124 & .161 & .185 \\
WORKINGPOP & 3124 & .507 & .052 \\
GPTERMS & 2714 & .002 & .002 \\
DATABASE & 2719 & .006 & .009 \\
HOURS & 2720 & .329 & .333 \\
\hline
\end{tabular}


Table 3: Correlations

\begin{tabular}{|c|c|c|c|c|c|c|c|c|}
\hline & 1 & 2 & 3 & 4 & 5 & 6 & 7 & 8 \\
\hline 1.INCOME2013 & - & & & & & & & \\
\hline 2.INCOME2012 & $.918^{* *}$ & - & & & & & & \\
\hline 3.BROADBAND & $.228 * *$ & $.238 * *$ & - & & & & & \\
\hline 4.HSCHOOL & $.606^{* *}$ & $.584 * *$ & $.180 * *$ & - & & & & \\
\hline 5.MINORITY & $146^{-*}$ & $-.048^{* *}$ & -.015 & $404 * *$ & - & & & \\
\hline $\begin{array}{l}\text { 6.WORKINGPO } \\
P\end{array}$ & $-.21 * *$ & $.136^{* *}$ & $.221 * *$ & $-.037^{*}$ & $.214^{* *}$ & - & & \\
\hline 7.GPTERMS & $057 * *$ & $-.101 * *$ & $241^{-\cdot}$ & .037 & $-.076^{* *}$ & $303^{--*}$ & - & \\
\hline 8.DATABASE & $057^{-}$ & $-.146^{* *}$ & $264 * *$ & $.069 * *$ & $-.149 * *$ & $459^{* *}$ & $.452 * *$ & - \\
\hline 9.HOURS & $081^{* *}$ & $-.161^{* *}$ & $335^{-}$ & $.085^{* *}$ & $-.189 * *$ & $481^{* *}$ & $.726^{* *}$ & $.626^{* *}$ \\
\hline
\end{tabular}

$* * p<.01$.

$* p<.05$.

Multiple specifications of the basic model were run with the natural logarithm of household income in 2013 as the dependent variable, including in each model all the demographic variables and one of the CTC quality variables as predictors. Alternative models with and without broadband availability were run for each CTC quality variable. The results are reported in Table 4.

In general, the models displayed stable coefficients under various specifications, and in most cases the coefficients were significant in the expected direction. Model statistics, including the R2 and the F-statistic, suggest that the models have considerable explanatory power. Given the persistence of household incomes from year to year, the coefficient on LOGINCOME2012 was strongly positive and significant. BROADBAND had a significant positive impact on household income in all three models in which it was included. This too is expected from theory, since the literature show that that broadband availability will enhance economic activity and contribute positively to employment, wages and income.

The demographic variables too had significant coefficients in the expected directions. Whereas better-educated communities, that is those with a higher percentage of adults with at least a high school education (HSCHOOL), had higher household incomes, 
communities with higher percentages of minorities (MINORITY) had lower incomes, other factors being constant. Finally, labor supply as predicted by economic theory, tended to depress median household incomes. Communities with a higher percentage of people in the 22-59 working age brackets (WORKINGPOP), had lower household incomes.

We now turn to our main research question, namely the impact of CTC services on economic growth, specifically household income. All three proxies used for the quality of CTC services had consistently positive and significant, though small coefficients. Given the magnitude of the coefficients, the impact of CTCs on economic growth is small. We can quantify this impact as follows: from Table 2, the average number of general purpose computer terminals (GPTERMS) available in public libraries is 0.002 , or 2 per 1000 of county population. Doubling this number to 4 per 1000 of population will increase the county median household income by $0.0015 \%$. A rough calculation suggests that this translates into an economic value of approximately $\$ 26,000$ on average annually in each county. Though additional costs will be incurred in installing and maintaining CTC facilities and services, it is evident from this analysis that a substantial part of those investments may be recoverable in the form of fostering economic growth and higher incomes in the community.

Table 4: Regression Analyses

\begin{tabular}{lllllll}
\hline & Model 1 & Model 2 & Model 3 & Model 4 & Model 5 & Model 6 \\
\hline CONSTANT & 2.060 & 2.095 & 1.818 & 1.849 & 1.893 & 1.907 \\
& {$[.094]^{* * *}$} & {$[.094]^{* * *}$} & {$[.095]^{* * *}$} & {$[.095]^{* * *}$} & {$[.097]^{* * *}$} & {$[.097]^{* * *}$} \\
& 22.024 & 22.288 & 19.120 & 19.452 & 19.423 & 19.626 \\
LOGINCOME2012 & .809 & .805 & .832 & .827 & .820 & .816 \\
& {$[.010]^{* * *}$} & {$[.010]^{* * *}$} & {$[.010]^{* * *}$} & {$[.010]^{* * *}$} & {$[.010]^{* * *}$} & {$[.010]^{* * *}$} \\
BROADBAND & 78.768 & 77.875 & 81.455 & 80.667 & 79.428 & 79.013 \\
& & .039 & & .052 & & .055 \\
HSCHOOL & & {$[.012]^{* * *}$} & & {$[.012]^{* * *}$} & & {$[.012]^{* * *}$} \\
& & 3.223 & & 4.297 & & 4.514 \\
& .173 & .166 & .160 & .151 & .163 & .151 \\
MINORITY & {$[.030]^{* * *}$} & {$[.030]^{* * *}$} & {$[.029]^{* * *}$} & {$[.029]^{* * *}$} & {$[.030]^{* * *}$} & {$[.030]^{* * *}$} \\
& 5.794 & 5.549 & 5.468 & 5.194 & 5.514 & 5.118 \\
& -.091 & -.092 & -.071 & -.070 & -.079 & -.078 \\
& {$[.012]^{* * *}$} & {$[.012]^{* * *}$} & {$[.012]^{* * *}$} & {$[.011]^{* * * *}$} & {$[.012]^{* * *}$} & {$[.012]^{* * *}$} \\
& -7.801 & -7.868 & -6.194 & -6.128 & -6.807 & -6.699 \\
WORKINGPOP & -.188 & -.204 & -.085 & -.103 & -.123 & -.135 \\
& {$[.038]^{* * *}$} & {$[.039]^{* * *}$} & {$[.039]^{*}$} & {$[.039]^{* *}$} & {$[.040]^{* *}$} & {$[.040]^{* * *}$}
\end{tabular}




\begin{tabular}{|c|c|c|c|c|c|c|}
\hline & -4.908 & -5.290 & -2.184 & -2.641 & -3.117 & -3.417 \\
\hline \multirow[t]{3}{*}{ GPTERMS } & .007 & .008 & & & & \\
\hline & {$[.003]^{* *}$} & {$[.003]^{* *}$} & & & & \\
\hline & 2.576 & 3.130 & & & & \\
\hline \multirow[t]{3}{*}{$D A T A B A S E$} & & & .015 & .016 & & \\
\hline & & & {$[.001]^{* * *}$} & {$[.001]^{* * *}$} & & \\
\hline & & & 10.274 & 10.924 & & \\
\hline \multirow[t]{3}{*}{$H O U R S$} & & & & & .015 & .018 \\
\hline & & & & & {$[.003]^{* * *}$} & {$[.003]^{* * *}$} \\
\hline & & & & & 5.864 & 6.905 \\
\hline$N$ & 2629 & 2629 & 2597 & 2597 & 2637 & 2637 \\
\hline Prob $>F$ & $* * * .000$ & $* * * .000$ & $* * * .000$ & $* * * .000$ & $* * * .000$ & $* * * .000$ \\
\hline $\mathrm{R}^{2}$ & .828 & .829 & .836 & .837 & .831 & .832 \\
\hline Adj. $\mathrm{R}^{2}$ & .828 & .829 & .836 & .837 & .831 & .832 \\
\hline
\end{tabular}

\section{Conclusions}

Though CTCs provide a host of services that might have economic consequences, such as digital literacy training, small business services, job training, etc., few attempts have been made to empirically assess the downstream economic impacts of investments in CTCs. This paper was an attempt to assess the impact of CTCs on one measure of local economic growth, namely median household incomes. Using the county as the unit of analysis, we estimated the impact of several markers of CTC quality such as the number of general purpose computer terminals available in public libraries and the number of publicly accessible electronic databases, on median household incomes. We controlled for other factors such as broadband availability, demographics and education in assessing this impact. Our results show that there is a small, but consistent, positive and significant impact of CTC quality on median household incomes. In addition to bridging the digital divide for disadvantaged populations, our research shows that there are also quantifiable economic benefits from CTC investments. This finding strengthens the case for continuing support for CTCs and PCCs that provide vital community resources.

However, there are several limitations and drawbacks to this study that may be remedied in future research. First, non-availability of data limited our analysis to only those CTCs attached to public libraries for which data were available from the IMLS. In addition, CTCs are often operated by a number of other entities such as municipal 
governments, charitable foundations, school districts etc. Since a national database on these institutions is not available, we did not include these in our analysis. In effect, the impact of CTCs may be overestimated in this analysis since we are undercounting the CTC resources available to communities.

Second, we lacked data on the actual economically-relevant activities performed by CTCs, such as the number of digital literacy or small business classes conducted by them, and the number of persons who participated in these activities. In the absence of this data, we used proxies for CTC quality such as the number of general purpose computer terminals and database availability that only imperfectly capture the quantity and quality of economically-relevant activities conducted by CTCs. Better data in the form of a survey of CTCs might help address this concern.

Third, median household income, while a proxy for economic growth, is not sufficient to capture all economic activity at the community level. For one, household income also includes non-wage incomes such as pensions and investment returns, rents and royalties, etc. Changes in income sources may not be attributable to local economic conditions. Future research may base its analysis on better measures of local economic performance.

Fourth, the present study has taken an econometric approach to studying the impact of CTCs on community economic development. While the data and subsequent analysis suggest a positive relationship between CTCs and household income, the present study does not fully account for the cognitive aspects of usage, and the consequent economic impacts of broadband. The digital literacy literature shows that differences in cognitive skills are critical elements of the digital divide, and therefore of the economic impacts of broadband. However, there is insufficient data to include digital literacy as a predictor variable in a large-sample statistical analysis. Therefore, we propose that education levels might be a reasonable proxy for cognitive skills. While we believe that this is a reasonable proxy, it is not a perfect one, and future research may investigate the relationship between the capacity of user populations to utilize broadband and the impacts on economic growth.

Finally, there may be regional and structural differences between our units of analysis that are not fully represented in the models. We have attempted to account for these time-invariant, location-specific factors by including prior-year median household income as a control. But not all relevant variables are time-invariant, and future research may explore more fully the structural economic characteristics and regional differences between counties.

Despite these limitations, the results in this paper suggest that considerations of not just equity and social justice but also those of economics justify continuing support for CTCs and other community institutions. The literature has plenty of case examples of individuals and communities that have benefited from the small business services and employment training services offered by CTCs. Our research complements this literature by empirically demonstrating quantifiable and significant benefits to CTC investments. 


\section{References}

Ariyabandu, R. (2009). Role of telecenters as knowledge networks: Successes and challenges. ESCAP Technical Paper, IDD/TP-09-06. Bangkok, Thailand: United Nations Economic and Social Commission for Asia and the Pacific. Retrieved from http:// telecentres.mfep.gov.dz/fileadmin/user_upload/bibilio_files/Role of telecentre.pdf

Atasoy, H. (2013). the effects of broadband internet expansion on labor market outcomes. ILR Review, 66(2), 315-345. doi:10.1177/001979391306600202

Bach, A., Shaffer, G., \& Wolfson, T. (2013). Digital human capital: Developing a framework for understanding the economic impact of digital exclusion in low-income communities. Journal of Information Policy, 3, 247-266. doi:10.5325/jinfopoli. 3.2013.0247

Crandall, R. W., Lehr, W., \& Litan, R. E. (2007). The effects of broadband deployment on output and employment: A cross-sectional analysis of U.S. data. The Brookings Institution: Issues in Economic Policy No. 6. Retrieved August from http://www.brookings.edu/ papers/2007/06labor_crandall.aspx

Cronin, F., Parker, E., Colleran, E. \& Gold, M. (1993). Telecommunications infrastructure investments and economic development. Telecommunications Policy, 17, 415-430.

Czernich, N., Falck, O., Kretschmer, T., \& Woessmann, L. (2011). Broadband infrastructure and economic growth. The Economic Journal, 121(552), 505-532. doi:10.1111/j. 1468-0297.2011.02420.x

Department of Commerce (2009). Notice of Funds Availability (NOFA) for broadband initiatives program and broadband technology opportunities program. Federal Register, 74(130), 33104-33134. Retrieved from http://www.ntia.doc.gov/files/ntia/publications/ fr bbnofa 090709.pdf

Fornefeld, M., Delaunay, G., \& Elixmann, D. (2008). The impact of broadband on growth and productivity. Brussels: European Commission, Directorate General of Information, Media and Society.

Gilster, P. (1997). Digital literacy. New York: Wiley Computer.

Goetz, S. J., Han, Y., Findeis, J. L., \& Brasier, K. J. (2010). U.S. commuting networks and economic growth: Measure and implications for spatial policy. Growth and Change 41(2), 276-302.

Gomez, R., Ambikar, R., \& Coward, C. (ed.) (2011). Libraries, telecenters and cybercafes: An international study of public access information venues. Hershey, PA: IGI Global/ Information Science Reference.

Gomez, R., and Camacho, K. (2013). Users of ICT at public access centers: Age, education, gender and income differences in users. In S. Chhabra (ed.), ICT influences on human development, interaction and collaboration (pp. 1-19). Hershey, PA: IGI Global/ Information Science Reference.

Haseloff, A. M. (2005). Cybercafés and their potential as community development tools in India. The Journal of Community Informatics, 1(3). Retrieved from http://www.cijournal.net/index.php/ciej/article/view/226/182

Jayakar, K., \& Park, E. (2012). Funding public computing centers: Balancing broadband availability and expected demand. Government Information Quarterly, 29(1), 50-59.

Jayakar, K. (2012). Between markets and mandates: Approaches to promoting broadband access for the disabled. Washington, DC: Time Warner Cable Research Program in 
Digital Communications. Retrieved from http://www.twcresearchprogram.com/pdf/ TWC Jayakar.pdf

Jipp, A. (1963). Wealth of nations and telephone density. Telecommunications Journal, 199-201.

Kaiser, S. (2005). Community technology centers and bridging the digital divide. Knowledge, Technology \& Policy, 18(2), 83-100.

Kent, D., \& McClure, D. P. (2009). Digital inclusion: Bringing the rest of America online with broadband. Alexandria, VA: Internet Industry Association.

Kolko, J. (2010). Does broadband boost local economic development? San Francisco, CA: Public Policy Institute of California. Retrieved from http://www.ppic.org/main/ publication.asp? $\mathrm{i}=866$

LaRose, R., Bauer, J. M., DeMaagd, K., Chew, H. E., Ma, W., \& Jung, Y. (2014). Public broadband investment priorities in the United States: An analysis of the broadband technology opportunities program. Government Information Quarterly, 31(1), 53. doi: 10.1016/j.giq.2012.11.004

London, R. A., Pastor, M., Servon, L. J., Rosner, R., \& Wallace, A. (2010). The role of community technology centers in promoting youth development. Youth \& Society, 42(2), 199-228.

Mandel, L. H., Bishop, B. W., McClure, C. R., Bertot, J. C., \& Jaeger, P. T. (2010). Broadband for public libraries: Importance, issues, and research needs. Government Information Quarterly, 27(3), 280-291.

National Telecommunications and Information Administration [NTIA] (2010). Broadband USA: Connecting America's communities. Program website. Washington, D.C: U.S. Department of Commerce. Retrieved from http://www2.ntia.doc.gov/about

O'Neil, D. (2002). Assessing community informatics: A review of methodological approaches for evaluating community networks and community technology centers. Internet Research, 12(1), 76-102.

Park, E., \& Jayakar, K. (2013). Implementation of BTOP funding for public computing centers: Goal consensus and project performance. Government Information Quarterly, 30(4), 514. doi:10.1016/j.giq.2013.07.002

Penuel, W. R., Michalchik, V. Kim, D., \& Shear, L. (2001). The organization of learning in community technology centers: Learning with technology in six communities. Menlo Park, CA: SRI International. Retrieved from http://www.sri.com/work/publications/ organization-learning-community-technology-centers-learning-technology-sixcommuni

Sey, A., \& Fellows, M. (2009). Literature review on the impact of public access to information and communication technologies. Seattle, WA: Center for Information and Society. Retrieved from http://library.globalimpactstudy.org/sites/default/files/docs/CISWorkingPaperNo6.pdf

Shideler, D., Taylor, L., \& Badasyan, N. (2007). The economic impact of broadband deployment in Kentucky. Regional Economic Development, 3(2), 88-118. Retrieved from https://research.stlouisfed.org/publications/red/2007/02/Shideler.pdf

Shuai, X. (2010). Who benefits from job creation at county level? An analysis of leakage and spillover of new employment opportunities in Virginia. Business Economics, 45, 38-48.

U.S. Dept. of Education (2004). Subpart 11 - Community technology centers. Retrieved from http://www2.ed.gov/policy/elsec/leg/esea02/pg77.html 
U.S. Dept. of Education. (2005). Frequently asked questions. Retrieved from http:// www2.ed.gov/programs/comtechcenters/faq.html

van Dijk, J. A. G. M. (2012). The evolution of the digital divide - the digital divide turns to inequality of skills and usage. In J. Bus, M. Crompton, M. Hildebrandt, \& G. Metakides (Eds.), Digital enlightenment yearbook (pp. 57-78). Amsterdam, Netherland: IOS Press.

Whitacre, B., Gallardo, R., \& Strover, S. (2014). Does rural broadband impact jobs and income? Evidence from spatial and first-differenced regressions. The Annals of Regional Science, 53(3), 649-670. 